Can ESA

members afford to fly on Spacelab?

THE UK and several other member states of the European Space Agency are having doubts about the cost of flying experiments aboard future missions of Spacelab, the Europeanbuilt space station which will be carried into orbit in the cargo bay of the US Space Shuttle. Response to ESA's call for experiments in April has been so good that if all the UK proposals (about 25) were recommended for flight (an admittedly unlikely eventuality), the total cost would come to perhaps double the $£ 25$ million annual outlay of the Science Research Council for all its astronomy, space, and radio activities.

In practice, preliminary ESA payload breakdowns are allowing the UK $13-14 \%$ of the Spacelab payload, but even this more realistic slice of the action would cost approximately $£ 3$ to $£ 4$ million per flight. Unless more money can be released from the research councils or the Department of Industry, the UK may be unable to afford this much. France, which is being offered a slightly greater percentage of the payload, is also expressing reservations about flight costs, as are Italy and the Netherlands. But Germany, which is largely responsible for the construction of Spacelab, seems to have no such worries, and has agreed to provide half the payload of the four missions being discussed.

These four European missions will follow the initial flights of Spacelab which have already been agreed. Payload space for Spacelab's first flight, now unofficially expected in April 1981, has been split between NASA and ESA, and NASA is offering a free launch. Spacelab 2, an American scientific mission, has some UK experiments on board, but these are being flown free as a cooperative venture. For the follow-on Spacelab missions, currently under discussion, the European experimenters will have to pay for the launch as well as the payload, and it is at this stage that several ESA member states are beginning to wonder what they have let themselves in for.

Two of the missions, referred to as D1 and D4, are being sponsored by the Germans, who are inviting other experimenters to join them on board. The other two missions, termed DM (Demonstration Mission) 1 and 2, are being paid for by ESA and the costs are being shared among the individual experimenters. Launch schedules will be clarified during the next three months, but as currently envisaged the German D1 mission will probably be the first to fly in June 1982. This will be a microgravity mission, concentrating on experiments on materials science and life science in weightlessness. Then will follow DM2, an Earth-oriented mission, in autumn 1982, with another micro-gravity mission, DM1, in mid1983. Last, because of its complexity, will be the German astronomy mission D4, probably in late 1983.

The SRC is now deciding which UK experiments it can support; part of its job has been to find sponsors for experiments in areas such as materials science and life sciences that do not come under its jurisdiction. The number of proposals vying for consideration is likely to drop as experimenters with common interests combine their activities to share costs, but there are bound to be some proposals that would be too big, too heavy, and thus too expensive, to gain support. Since most of the SRC's limited budget is already earmarked, the Council is unlikely to be able to afford more than a few million pounds for Spacelab experiments, meaning that it could support a total payload weight of only around 200 to $300 \mathrm{~kg}$ for the four missions.

One possibility is that the Department of Industry, which has so far paid the UK's $6.3 \%$ contribution to the cost of building Spacelab, might be persuaded to continue its support for Spacelab past the development stage, thus paying the boarding costs of experiments and leaving the research councils with only the funding of the actual experiments to worry about. But the drawback to this from the DoI's point of view is that relatively few experiments have so far been proposed by British industry, most of the response having come from universities and research establishments.

Ian Ridpath

\section{Space medicine: a Polish speciality}

DURING the 12 years of the Interkosmos programme of space cooperation between the countries of the socialist bloc, space medicine has become a Polish speciality. Not surprisingly, therefore, the flight of Miroslaw Hermaszewski as part of the current "international" manned-flight programme of Interkosmos included a number of medical experiments.

'These ranged from "zdrowie"-an estimation of physical efficiency by means of simultaneous ECG analysis, monitoring of the rate of cardiac con-

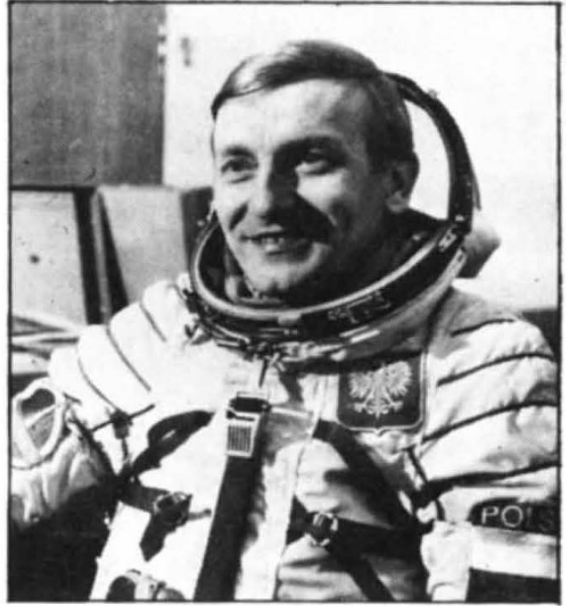

Polish cosmonaut Hermaszewski

tractions, blood pressure, respiration rate and body temperature--to the somewhat exotic "smak" experiment, to elucidate the "still unclear mechanisms of the taste disorders experienced by cosmonauts in orbit". The latter, which was contributed by the Polish Military Institute of Aviation Medicine, is based on the electrical stimulation of the taste buds.

The programme also included the "relaks" experiment, which estimates the influence of "recreation exercises" on the psychophysiological condition of the crew in the course of a prolonged flight, and the "kardiolider", which monitors cardiac strain to determine the physical effort exerted by a cosmonaut in various stages of the flight. The latter device, developed by the Warsaw Institute of Aviation Medicine, is said to be of particular use in monitoring physical exercises for cosmonauts in conditions of weightlessness, as well as their readaptation to the earth's gravitation on their return.

Stressing the contribution of the non-Soviet crew member to an "international" flight is, of course, important for purely diplomatic reasons. In the first such flight, earlier this ycar, considerable emphasis was placed on the Czechoslovak contribution - notably the Czech capsule "morava" which was used in conjunction with the Soviet "Splav" furnace as part of a series of experiments producing alloys which would be impossible under conditions of gravity. (The present mission included a similar joint experiment, with a Polish capsule code-named "syrena").

What is remarkable about the medical experiments is that both sides stress that they are predominantly a Polish contribution. According to veteran cosmonaut Vladimir Aksenov, interviewed on Moscow radio, the Poles are developing the experiments begun in the Soviet Union using their own methods and their own instruments. Vera Rich 